\title{
Dr. Bruce Squires, 1934-2011: CMAJ editor, mentor and friend
}

$\mathrm{D}$ r. Bruce Squires was once introduced to delegates at a Canadian Medical Association leadership conference as a worldrenowned leader on medical journals. He laughed at the notion, dismissing it in a recent interview as being "overblown," although he allowed that he "wrote about it more than others did."

The humble comment was typical of Squires, who in his lengthy career also became globally revered for his mentorship, his knowledge of journals and his unstinting sense of humour. Squires passed away on the morning of May 11, 2011, a day after celebrating his 77th birthday.

Squires was editor-in-chief at CMAJ from 1989 to 1996 . He began working at the journal in 1984 as an assistant editor, then scientific coeditor (1986), and scientific editor (1987) before assuming the journal's helm.

He was born May 10, 1934, in Toronto, Ontario and earned his Bachelor of Arts at the University of Western Ontario in London, Ontario. He subsequently obtained a medical degree (1958) and a doctorate in medical research (1962) from the same institution. Following a postdoctoral fellowship in endocrinology at Duke University Hospital in Durham, North Carolina, Squires returned to Western in 1965 as an assistant professor of physiology, rising to full professor status by 1982 .

Writing was always an integral part of his career. Six editions of his instructor's manual and study guide, Physiology of the Human Body (Saunders; 1979), were published and he penned an array of articles, including more than 120 editorials for CMAJ.

Over the course of career, his laurels multiplied. Western honoured him with the Douglas Bocking Award for excellence in medical education, while the
American Medical Writers Association named him an honourary fellow. For his many contributions, CMAJ created the Squires Award, which since 2008

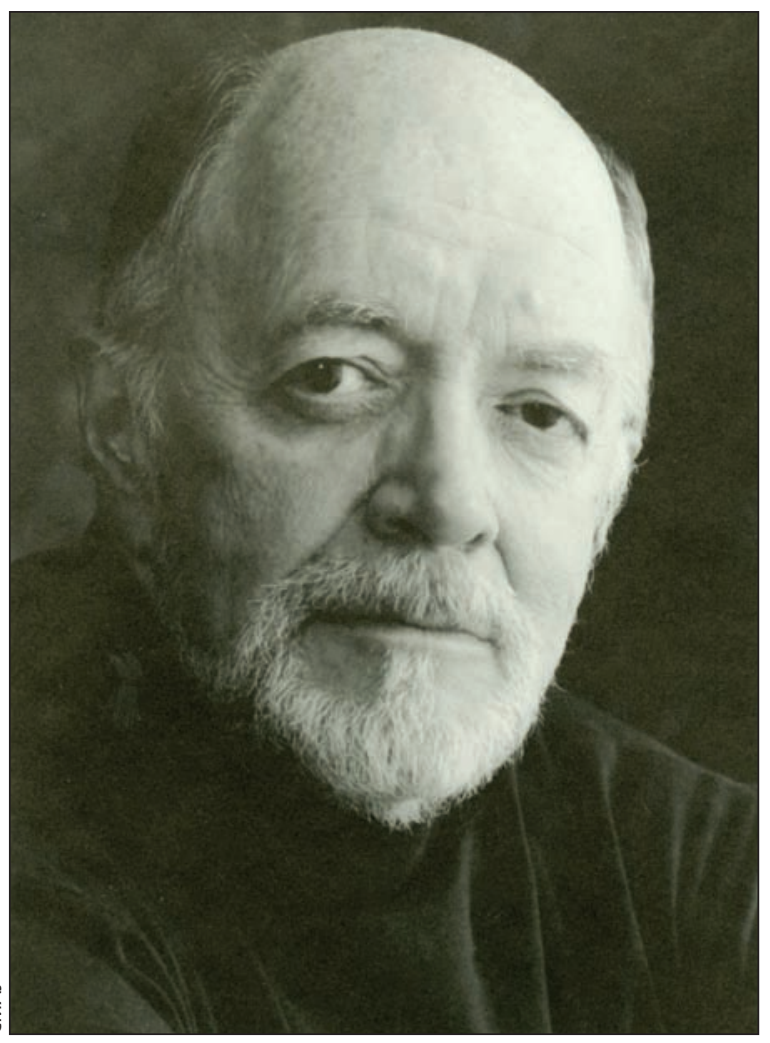

Dr. Bruce Squires (1934-2011) led CMAJ into an era of more rigorous scientific research publishing.

has been awarded annually to the authors of the journal's best research article in the calendar year.

In a recent interview for an article on CMAJ's 100th anniversary, Squires mused that the most significant change that occurred during his 13-year tenure at the helm of the journal was the increased pressure to publish quality research. The pressure was the product of demands from the International Committee of Medical Journal Editors, from researchers in Canada, and from the CONSORT group, which developed the Consolidated Standards of Reporting Trials to alleviate problems associated from inadequate reporting of randomized controlled trials. It forced much more rigorous and systematic appraisal of research, Squires said.

When he became editor-in-chief, $C M A J$ was primarily publishing observational studies, as it had since 1911, and the transition was tricky, Squires said. Ex-editor-inchief Peter J. Morgan "and I had a lot of intense arguments regarding what should be in a manuscript and how to do it."

But 22 years in academia served him well in effecting the necessary changes, Squires said.

For his part, Morgan says Squires' strength as an editor was his "careful use of language and precision," and the meticulous care he took with all facets of the journal. "He did improve the quality."

Squires threw himself wholeheartedly into improving the journal. Whereas editors of other journals weighed in on contentious public policy issues, he chose to scour his own backyard with editorials aimed squarely at improving research standards and reporting. His hugely popular series, "What editors want from authors and peer reviewers," covered the spectrum: from biomedical reviews to case reports, editorials to descriptive studies, biomedical statistics to illustrative materials.

"He was the first to formalize the peer review process at the journal and help authors, peer reviewers and, by extension, editors at other journals, to learn," says Kate Schissler, a manuscript editor at the journal since 1985.

"He was always willing to teach," she adds. "And had complete trust in us."

Dr. John Hoey, CMAJ's editor-inchief from 1996-2006, found that pedagogical inclination invaluable. "He was a wonderful warm human being without pretense who was always there for advice and guidance. He loved the journal, believed in it." 
Schissler also recalls Squires with fondness and admired his "infectious" sense of humour. "He must have been reincarnated from a clown; he loved to stir it up."

Pat Sullivan, who worked with Squires for a decade as CMAJ's news editor, concurs. "Bruce combined a superior intellect with a great sense of humour. ... Things were never dull. I'm one of many, many people who will miss him."

With that humour came solid principles, recalls former CMA publisher, Stephen Prud'homme. "He helped to frame for me - and the ICMJE [International Council of Medical Journal Editors] - ethical issues, such as a conflict-of-interest and privacy. He set his parameters and always took the high road."

He was also a "great friend, a mentor and a delight," Prud'homme adds.

Dr. Léo-Paul Landry, secretary general of CMA from 1986-99 was struck by Squires' lively, inquiring mind. "He took into account the context in which he worked and not everyone could do that."

"He wasn't living in the past, in fact, he was only partly living in the present. He was always curious, always trying to dig deeper," Landry adds. "As a colleague, he was the best I've ever met."

Add to those attributes and accomplishments an inspired leader in the world of medical journals. In 1995, Squires helped found the World Association of Medical Editors (www.wame.org), which he later described as having been "put together to help the smaller or poorer journals, most of which have part-time, volunteer editors with fixed terms and very little experience."

Squires was a "strong proponent from the word go," recalls Dr. Suzanne Fletcher, former coeditor, with her husband Robert, of the Annals of Internal Medicine. Squires conceived of having a virtual organization, held together by a listserv - an innovation at the time, Fletcher says. "He worked very hard on that listserv; it's the reason WAME has grown so much."

"He knew every one of the editors," Fletcher adds. "He's been called the godfather of WAME."

His success "had to do with his disarming sense of humour, friendliness, optimism, lack of pretension," says Dr. Robert Fletcher.

Squires was a mentor to editors in 77 countries, before stepping down from the association's board in 2004. But he continued to run its listserv for many years. WAME members now tally 965 journals in 92 countries.

"He united medical editors of the world," Dr. Ana Marušić, coeditor of the Croatian Medical Journal writes in an email. "He gave them strength of unity in the love for the editorial profession and the wealth of differences and visions. WAME is his legacy that lives on, ever stronger."

Always willing to donate time to the development of the world's journals, Squires participated in the founding meeting of the Forum of African Medical Editors. He was also an honourary member of the Eastern Mediterranean Association of Medical Editors.

After retiring from $C M A J$, Squires served as an adjunct professor (epidemiology and community medicine) at the University of Ottawa (20032006) in Ontario and a consulting medical editor. In 2006, he returned to the journal as editor emeritus.

He is survived by his wife of 47 years, Patricia (McBane), daughter Patti, son Bruce (vice-president, corporate affairs, CMA), daughter-in-law Joanne Kennedy and three grandchildren, Grady, Ella and Audrey. - Barbara Sibbald, CMAJ

CMAJ 2011. DOI:10.1503/cmaj.109-3896 